\title{
Graphite Formation and Dissolution in Ductile Irons and Steels Having High Silicon Contents: Solid-State Transformations
}

\author{
P. Rubin ${ }^{1,2} \cdot$ R. Larker $^{1,3} \cdot$ E. Navara ${ }^{4} \cdot$ M.-L. Antti ${ }^{1}$
}

Received: 21 December 2017 / Revised: 21 August 2018/Accepted: 22 August 2018/Published online: 7 September 2018

(C) The Author(s) 2018

\begin{abstract}
Graphite formation in the solid state is both in ductile cast irons and in steels strongly promoted by high silicon contents above $3 \mathrm{wt}$ \% Si. The matrix microstructure in austempered ductile iron can be further refined by secondary graphite if the austenitization, quench, and isothermal transformation into ausferrite are preceded by an austenitization at a slightly higher temperature followed by quench to martensite, resulting in higher carbon content than being soluble at the second austenitization temperature. Hypoeutectoid steels with high silicon contents can be rapidly graphitized, causing recrystallization of surrounding ferrite due to plastic deformation making room for less dense graphite. In rolled steels, the interface between manganese sulfide and steel matrix is the most common nucleation site. Voids are formed when graphite is partly or completely dissolved during austenitization in succeeding hardening heat treatments, but the mechanical properties can still be good if the graphite particles dissolved into voids are below $20 \mu \mathrm{m}$. Graphitized Si-solution strengthened ferritic steels may perform similar to free-cutting steels but with improved mechanical properties.
\end{abstract}

Keywords Graphitization · High silicon iron · High silicon steel · Machinability · Void formation · Ausferrite

\section{Introduction}

Graphite formation in iron-based materials offers increased degrees of freedom regarding a multitude of properties. So far it has mainly been utilized in iron castings where solidification shrinkage is counteracted by graphite

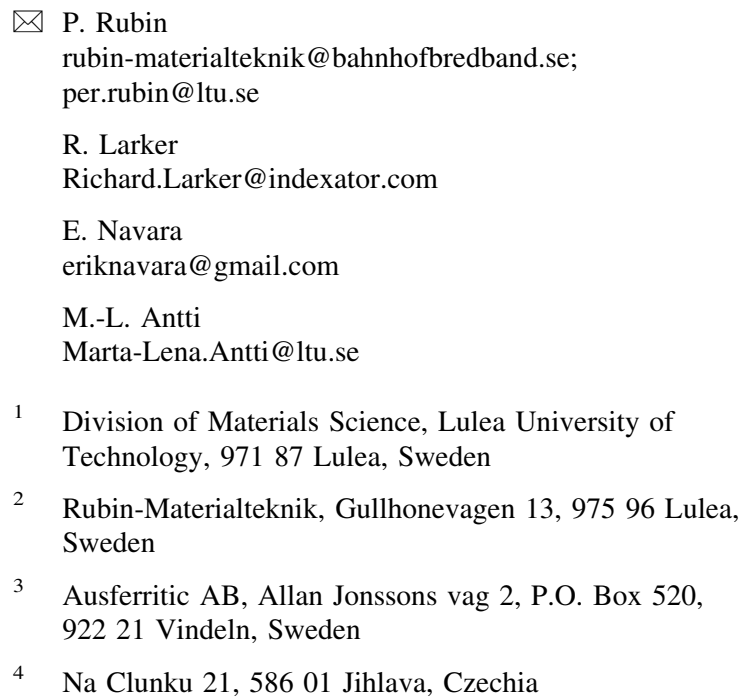

4 Na Clunku 21, 58601 Jihlava, Czechia

expansion, machinability is improved since graphite both acts as lubricant and results in discontinuous chips. Vibrations are damped and weight is reduced by approximately $8 \%$ compared to steel. In steels having by definition much lower carbon contents experiences are more mixed, including decreased mechanical properties at elevated temperatures due to unwanted graphitization and uneconomically long annealing requirements when graphitization is desired.

Two of the present authors have for more than a decade developed alloying and heat treatment know-how regarding austempering of high silicon spheroidal graphite cast irons to form Si-solution strengthened ausferritic ductile irons (ADI) and more recently austempering of high silicon medium carbon steels to form Si-solution strengthened ausferritic steels, both either austempered in salt baths or under very high isostatic argon gas pressure (170 MPa) in a hot isostatic press (HIP) equipped with Uniform Rapid Quenching (URQ ${ }^{\mathrm{TM}}$ ) as described in [1]. The third author has supervised research regarding the importance of the austenitization step for conventional ADI [2].

This paper will present some interesting observations where the common denominator in the three chosen 
examples is different aspects of solid-state transformations of graphite.

\section{The Metastable $\left(\mathrm{Fe}^{-} \mathrm{Fe}_{3} \mathrm{C}\right.$ ) and Stable (Fe-C) Phase Diagrams}

The metastable iron-cementite phase diagram is, by far, the most frequently used. This reflects the total dominance of unalloyed and low-alloyed steel in construction materials. The occurrence of graphite is mostly unwanted, and stringent regulations are in use for processes which expose the steels to heat in excess of $400{ }^{\circ} \mathrm{C}$.

In iron foundries, the stable iron-graphite diagram is dominating. By introduction of substantial amounts of silicon (>1 wt.\% Si) into a ternary $\mathrm{Fe}-\mathrm{C}-\mathrm{Si}$ composition with silicon atoms substituting iron atoms in the lattice, graphite formation is favored instead of cementite. The origin of cast irons, usually named gray iron, has a steel matrix (ferritic, ferritic-pearlitic or pearlitic) with lamellar graphite. The silicon content is typically in the range 2-3 wt.\% Si. The graphite lamellas are the weak link limiting ductility and the fracture surface is gray/black, hence its name.

During the end of the 1940s, an alternative route was introduced by adding magnesium [3] or cerium to the melt. This resulted in spheroidal graphite and a metallic luster in fracture. The group was named ductile iron since the elongation at fracture commonly exceeds $10 \%$ for ferritic matrices. Gray iron is still dominating the iron foundries in tonnage although the use of the tougher ductile iron is increasing, often substituting steel castings due to better castability and machinability as well as lower weight and cost. The graphite spheroids are nucleated and grown in the melt, to a size in the range $10-100 \mu \mathrm{m}$ depending on the solidification time in thinner or thicker castings.

Before the advent of ductile iron, an earlier solution to the problem with low ductility in gray iron was to heat treat initially hard and brittle white irons (named due to their white fracture surface) having only about $1 \mathrm{wt} . \% \mathrm{Si}$ and a martensitic-ledeburitic matrix. The process carried out in the austenitic field is called malleabilizing (to make the iron malleable). The end result is a ferritic matrix with graphite in the form of so-called temper-carbon with sizes around $10 \mu \mathrm{m}$.

The lower parts of austenitic fields in the two-phase diagrams are, for the sake of reasoning, almost the same. The slight modifications can be seen in Fig. 1 taken from Hultgren [4]. In this figure, the dashed lines represent the stable system. It is important to note that alloying with higher silicon contents shifts the eutectoid point $\left(S\right.$ and $\left.S^{\prime}\right)$ in both phase diagrams, mainly to higher temperatures

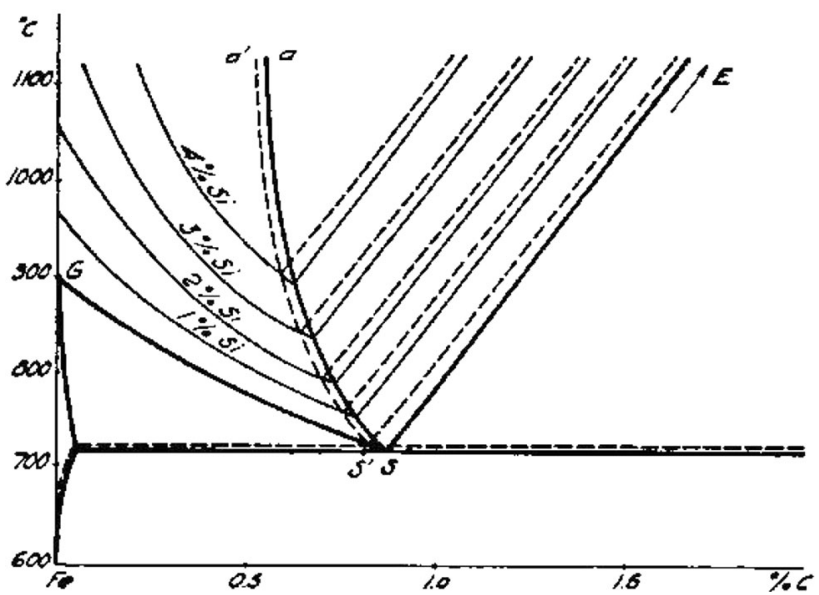

Fig. 1 Influence from $\mathrm{Si}$ on austenite fields in stable and metastable $\mathrm{Fe}-\mathrm{C}-\mathrm{Si}$ systems, after Hultgren [4]

since $\mathrm{Si}$ is a strong ferrite stabilizer, but also shifts $\mathrm{S}$ and $\mathrm{S}^{\prime}$ to lower carbon contents.

The first (as far as the authors are aware) development of an intentionally graphitic steel was made by the Timken Company in the early 1930s [5-10]. The group was led by Frederick R. Bonte. A whole family of steels was produced. The basic idea was to choose a hypereutectoid carbon level and a silicon level slightly below $1 \mathrm{wt} . \% \mathrm{Si}$. When slowly cooled after hot working or reheated in the austenitic field, the excess carbon forms graphite. The steel matrix was ferritic-pearlitic or, after renewed austenitization followed by quenching, martensitic. Graphite content was usually 1 vol.\%. Advantages include better machinability and lower adhesive wear in die applications.

A later path has been the graphitisation of hypoeutectoid steels. In this case, the carbon solubility with temperature in austenite is not a parameter, since the graphitization takes place in ferrite after prior spheroidization of pearlite, so-called subcritical annealing. Examples of early work are Austin et al. [11], Dennis [12] and Hickley et al. [13], with typical nodule size $5 \mu \mathrm{m}$.

\section{Secondary Graphite in Ductile Cast Irons}

Silicon suppresses cementite formation from the melt. In solid-state transformations of austenite at intermediate temperatures, silicon promotes ferrite but is not so efficient in preventing cementite growth within pearlite. At lower temperatures, the effect of silicon increases again, where its destabilization of cementite in the traditional bainite range 250-400 ${ }^{\circ} \mathrm{C}$ delays or completely prevents the formation of bainite during austempering heat treatments and instead ausferrite is formed, being a mixture of acicular ferrite and carbon-stabilized austenite. 
In steels Le Houllier et al. [14] in 1971 were the first to conclude about this novel structure that “... what appears to be bainite under the optical microscope at $1000 \times$ and what has been called apparent bainite must contain a substantial amount of retained austenite." Understanding the strong influence from silicon may, however, have been concealed by an unfortunate printing error in Table 1 of their paper, stating that the SAE 9262 steel contained 0.036 wt.\% Si, while this high silicon steel alloy contains 1.8-2.2 wt.\% Si. Pragmatic consensus in the technical society is that $1.5 \mathrm{wt} . \% \mathrm{Si}$ or more is needed for the shift from bainitic to ausferritic transformations.

In ductile irons, due to their higher silicon content compared to most conventional steels, ausferritic microstructures have a longer history. Already 1949 in the first ductile iron patent [3] by Millis et al., austempering was described as Heat treatment \#1 in Table XIII, using austenitization at $843{ }^{\circ} \mathrm{C}\left(1550{ }^{\circ} \mathrm{F}\right)$ followed by quench into a salt bath at $427^{\circ} \mathrm{C}\left(1550{ }^{\circ} \mathrm{F}\right)$ and held $5 \mathrm{~h}$ for isothermal transformation into ausferrite. Unfortunately their alloys with $2.1-2.3 \% \mathrm{Si}$ also contained high manganese levels at $0.8-0.9 \mathrm{wt} . \% \mathrm{Mn}$ (being typical for gray irons with lamellar graphite), causing incomplete transformation into ausferrite and therefore inferior ductility in the range $A_{4}=0.5-1.5 \%$.

The increasing carbon solubility in the austenite with increasing temperature (see line S-E in Fig. 1) can for ductile irons having graphite spheroids as carbon reservoirs be used to refine the ausferritic matrix structure a magnitude further. If the material is preconditioned by quenching to martensite from a higher austenitization temperature, the second austenite will due to its lower carbon solubility precipitate the excess carbon as a fine dispersion of secondary graphite. During the isothermal transformation after quench in the salt bath, these small nodules promote

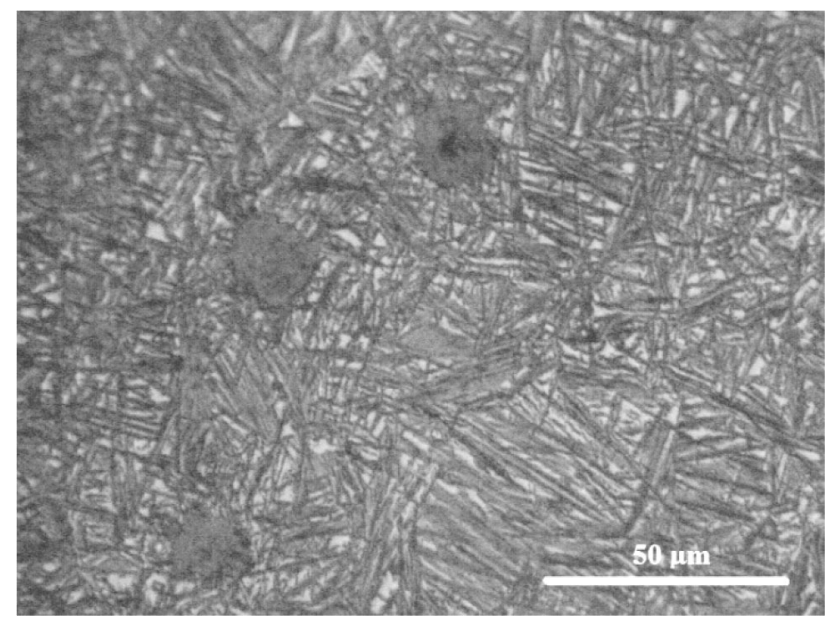

Fig. 2 ADI austempered after austenitization of the as-cast ferriticpearlitic matrix [15] nucleation of finer ferrite in a morphology that resembles so-called acicular ferrite in low carbon steel welds.

Figures 2 and 3 show at equal magnification samples taken from the same spheroidal graphite cast iron alloy with $3.8 \mathrm{wt} . \% \mathrm{Si}$ after the same austempering heat treatment [15]. The alloy is based on the Si-solution strengthened ferritic ductile iron grade GJS-500-14 in EN 1563:2011 [16]. The difference is the microstructure before the austempering heat treatment: The first sample in Fig. 2 started with austenitization of the as-cast ferriticpearlitic matrix (where pearlite was promoted by alloying with $\mathrm{Ni}, \mathrm{Cu}$, and Mo for increased hardenability), while the precursor for the austempering treatment of the second sample in Fig. 3 started with martensite quenched in water from a prior austenitization at $10 \mathrm{~K}$ higher temperature (dissolving more carbon), thus having higher carbon content than being soluble in the austenitization step (same as

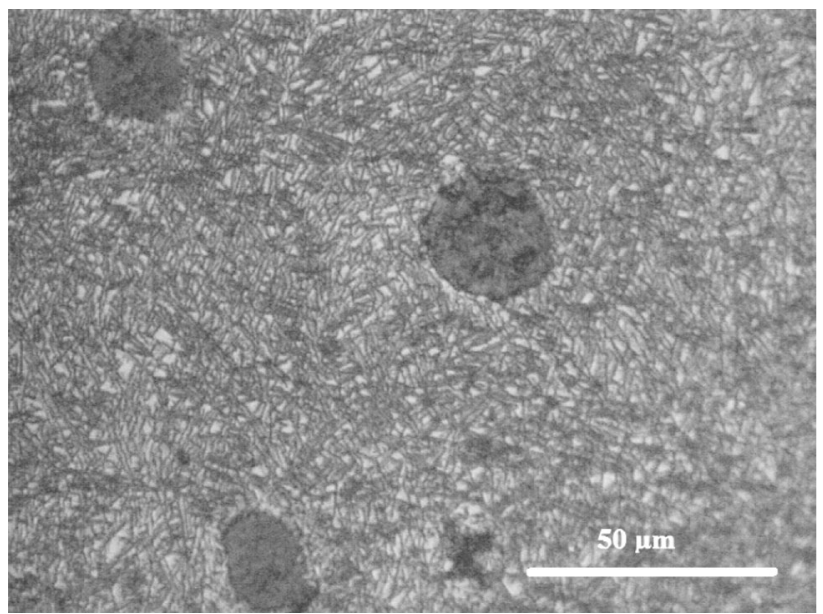

Fig. 3 ADI austempered with the same parameters but with martensite as precursor [15]

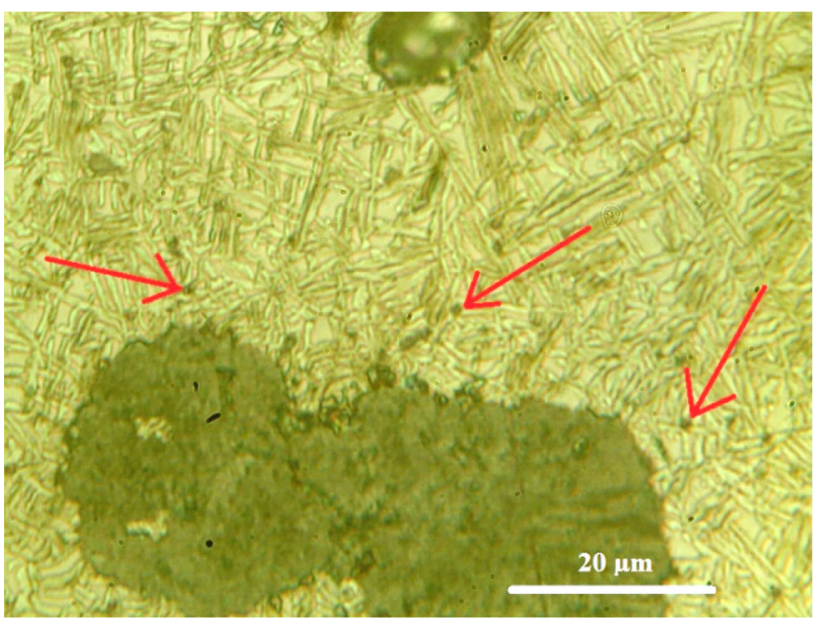

Fig. 4 Nucleation of ausferrite at secondary graphite spheroids [17] 
in Fig. 2) before quench in salt during the austempering treatment.

Figure 4 illustrates specific nucleation positions of ausferrite formation at secondary graphite spheroids after heat treatment specified in Fig. 3 [17], while Fig. 5 shows a fracture surface of the same material [18]. Typical size of the secondary graphite spheroids is $1 \mu \mathrm{m}$, while primary graphite spheroids are between one and two orders of magnitude larger.

In spite of the fine ausferrite structure nucleated on fine secondary graphite, mechanical properties were similar as those obtained with the same heat treatment but without secondary graphite [18]:

With secondary graphite: $R_{\mathrm{p} 0.2}=834 \pm 14 \mathrm{MPa}$; $R_{\mathrm{m}}=1149 \pm 11 \mathrm{MPa} ; A_{5}=6.1 \pm 0.4 \%$.

Without secondary graphite: $R_{\mathrm{p} 0.2}=910 \pm 3 \mathrm{MPa}$; $R_{\mathrm{m}}=1233 \pm 6 \mathrm{MPa} ; A_{5}=5.6 \pm 0.3 \%$.

Another way of achieving this refining effect is by executing the austenitization in two steps, starting at a higher austenitization temperature where the solubility of carbon is higher and then allowing the iron to cool to a lower austenitization temperature before quench in the salt bath. Our experience is that in this case, a much larger difference in temperature exceeding $150 \mathrm{~K}$ is needed.

Azevedo [19] has published some results on austempering either with preceding quench to martensite or with two-step austenitization using a temperature difference of $200 \mathrm{~K}$.

\section{Graphite Formation in High Silicon Medium Carbon Steels}

The challenge of finding a physical model of graphite growth in ferrite has been discussed since the 1950s, see for example Hillert [20]. Even if carbon diffuses sufficiently

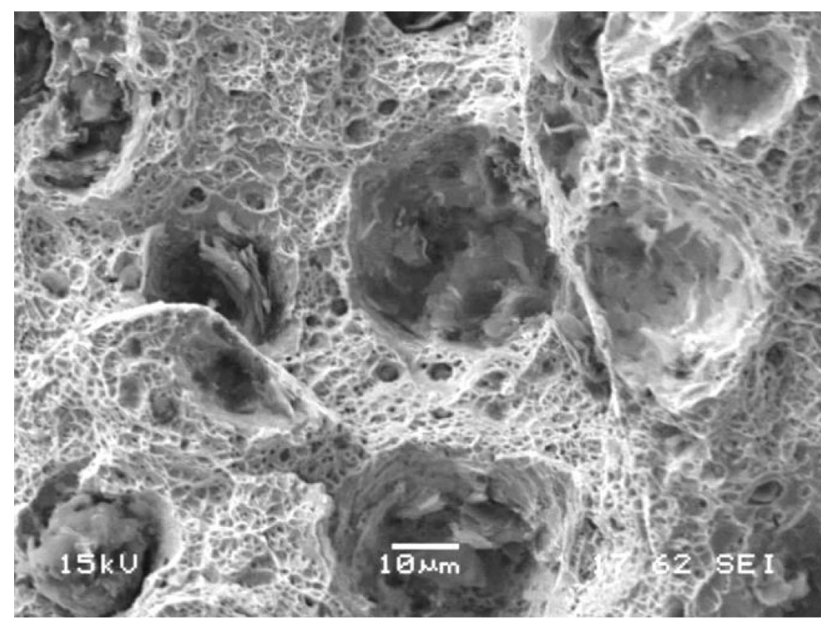

Fig. 5 Secondary graphite in tensile ductile fracture surface [18] rapid through the iron matrix in the temperature range $700-800{ }^{\circ} \mathrm{C}$ to form graphite precipitates, diffusion of iron away from the vicinity of the graphite is much too slow.

Subcritical annealing of hypoeutectoid steel has gained renewed interest. The most active European group is led by Prof. Edmonds at Leeds University; see chosen examples in [21-25].

Among other groups, especially noteworthy is the work in Italy by Borruto and Felli [26]. They annealed a steel composition containing $0.4 \mathrm{wt} . \% \mathrm{C}$ and $2.6 \mathrm{wt} . \% \mathrm{Si}$, transforming the mainly pearlitic initial structure into ferrite and nodular graphite in $1 \mathrm{~h}$.

The present authors have used material from a 1 tonne steel ingot (cross section $300 \times 300 \mathrm{~mm}$ ) firstly forged to a $165 \times 165 \mathrm{~mm}$ billet followed by rolling to $200 \times 10 \mathrm{~mm}$, as well as keel blocks poured from the same melt containing $0.5 \mathrm{wt} . \% \mathrm{C}$ and $3.8 \mathrm{wt} . \% \mathrm{Si}$, see Figs. 6, 7, 8, 9, and 10 .

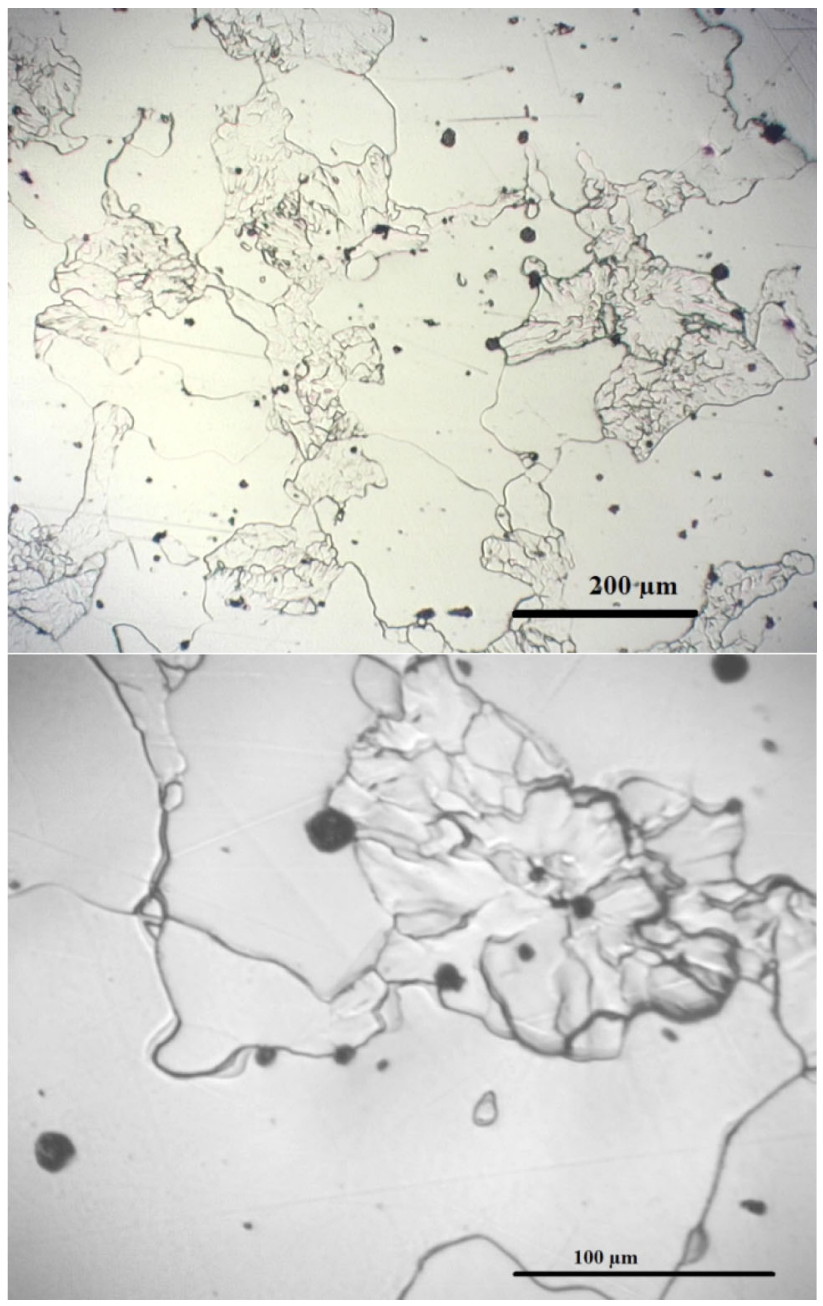

Fig. 6 a High-Si medium-C steel graphitized at $720^{\circ} \mathrm{C}$ for $5 \mathrm{~h}$, showing recrystallized ferrite near some of the graphite spheroids; b Close-up of one recrystallized ferrite area 


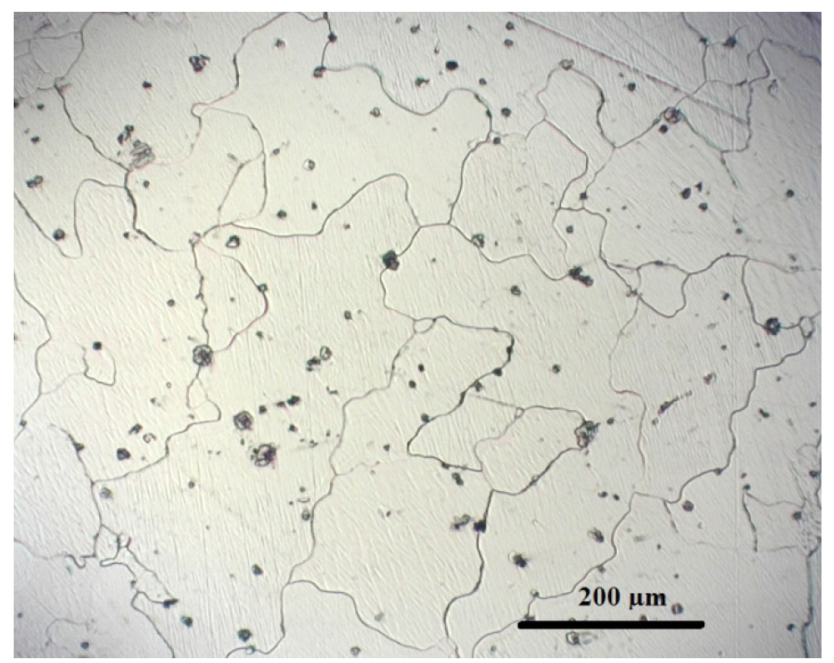

Fig. 7 High-Si medium-C steel graphitized at $720{ }^{\circ} \mathrm{C}$ for $24 \mathrm{~h}$, showing equalization of ferritic grain sizes at longer durations by growth of prior recrystallized ferrite

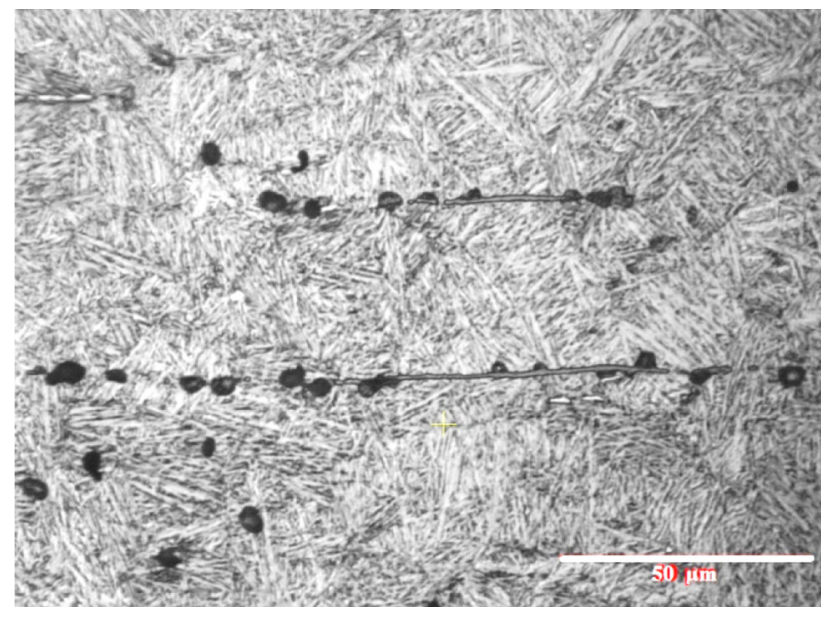

Fig. 8 Rolled and graphitized steel after austempering, showing voids where dissolved graphite spheroids were preferentially nucleated on manganese sulfides elongated in the horizontal rolling direction

The transformation is surprisingly rapid. At $790{ }^{\circ} \mathrm{C}$, the graphitization is finished in $1-1.5 \mathrm{~h}$. The reason for the slightly faster graphitization by Borruto and Felli may, despite our higher silicon content, be that our alloy contained more manganese and also some chromium being very efficient in stabilizing cementite [20].

During more sluggish transformations at lower temperatures, one extraordinary observation was made after $5 \mathrm{~h}$ at $720{ }^{\circ} \mathrm{C}$ : The growth process recrystallizes some of the ferrite surrounding the spheroids, see Fig. 6a and b. Why? A plausible theory may be that in order to make the quick transformation possible, the ferritic matrix has to be plastically deformed to make room for graphite spheroids, occupying a volume of about 2 vol. $\%$ in fully graphitized 0.5 wt. \% C steel.

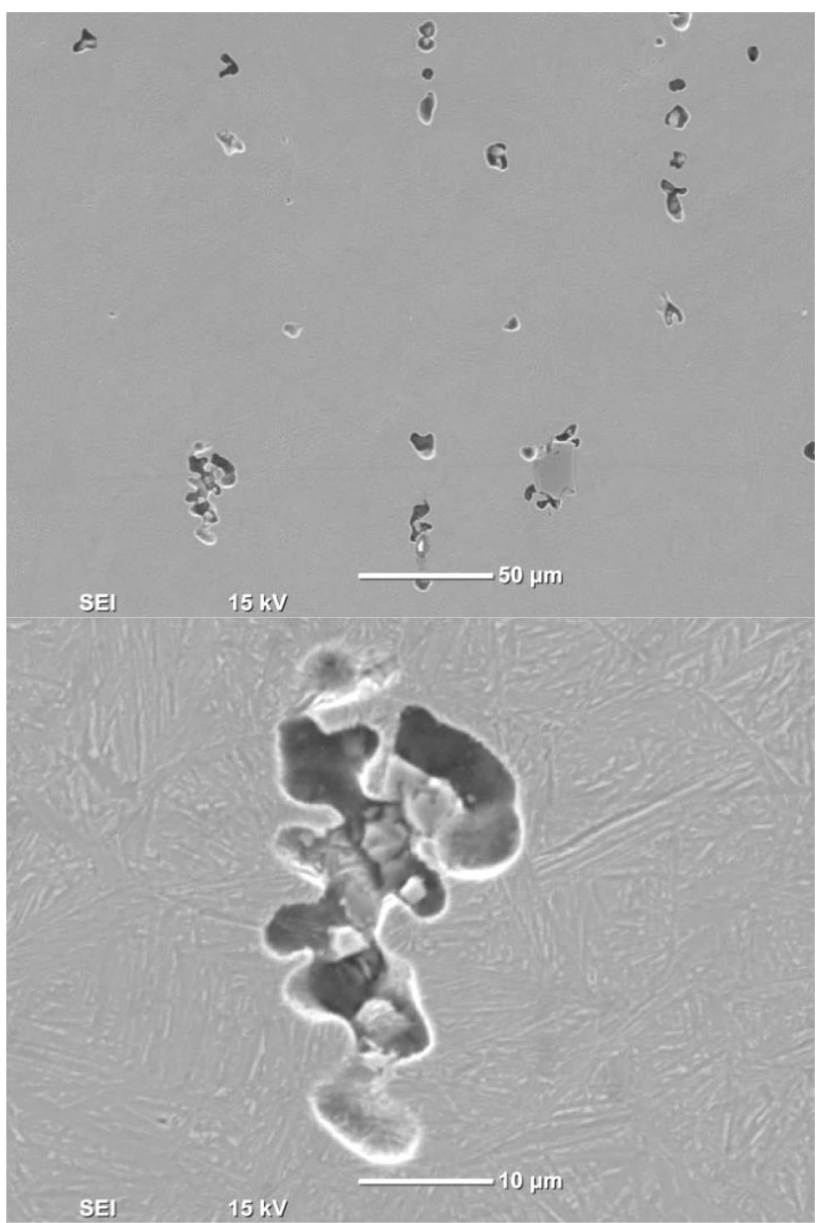

Fig. 9 a Voids after dissolution of graphite, vertical rolling direction; b close-up at a void

After longer duration for $24 \mathrm{~h}$, recrystallized grains grow to sizes similar to those further away from the graphite spheroids, see Fig. 7.

These samples were taken from keel blocks poured from the same melt as the 1 tonne ingot. They had a starting structure of as-cast pearlite, since the high silicon content moves the carbon content in pearlite to lower levels compared to conventional steels, see Fig. 1.

Figures of locally formed fine ferritic grains adjacent to precipitates of graphite have been published at least once before by Harris et al. [27] in 1965, but this phenomenon of plastically deformed and recrystallized ferritic grains in the process of graphitization appears to be overlooked by the scientific community.

When hot-rolled long products from the $300 \times 300 \mathrm{~mm}$ ingot forged to $165 \times 165 \mathrm{~mm}$ followed by rolling to $200 \times 10 \mathrm{~mm}$ (with a pearlitic structure as-rolled) of the same medium carbon high silicon steel were heat-treated for graphitization, it was found that interfaces between elongated manganese sulfides and steel matrix were the most common nucleating sites, see Fig. 8 . 


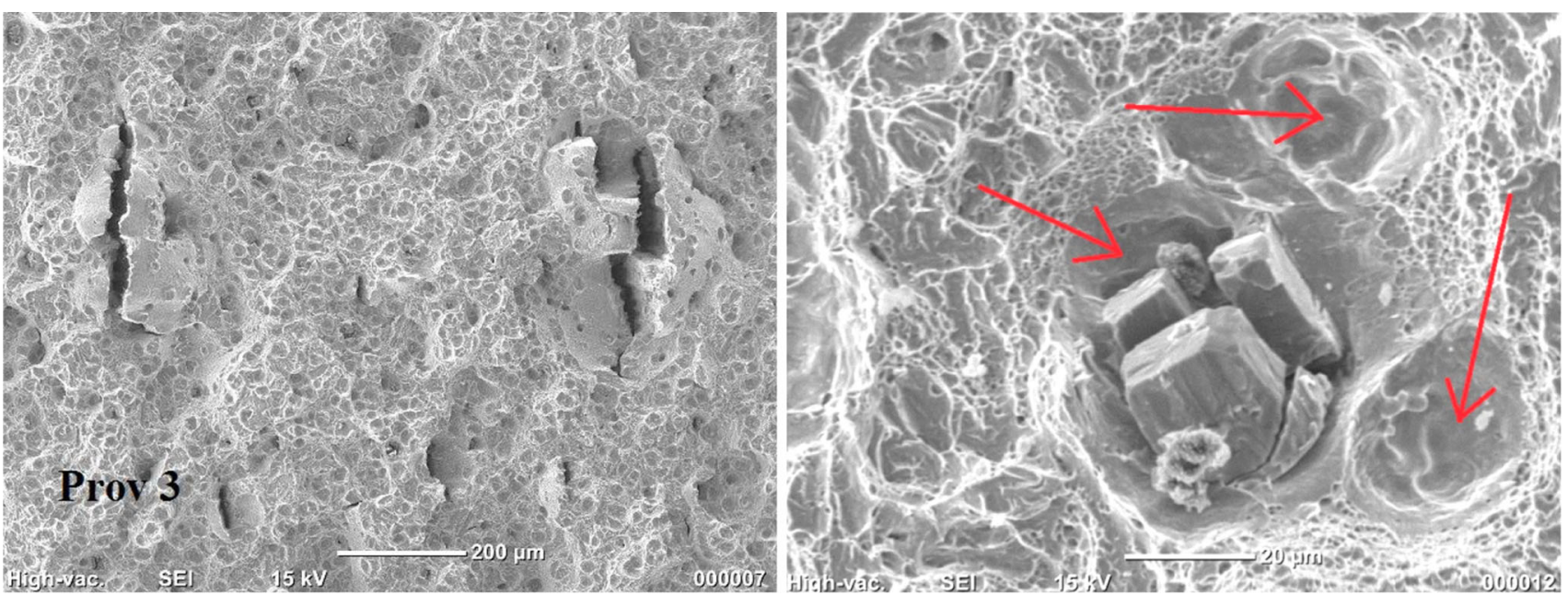

Fig. 10 a, b Charpy V fracture surface of ausferritic steel after graphitization and austempering

The literature on graphitization of steels so far has focused on nitrides and carbides as nucleating agents, see examples in [28-31]. It appears that the role of MnS is overlooked.

\section{Dissolution of Graphite: Formation of Voids}

Graphitized steels may offer a beneficial microstructure after hot rolling and annealing, either used as a mediumstrength steel with improved mechanical properties due to solution strengthened ferrite replacing pearlite (similar to the three Si-solution strengthened ferritic ductile iron grades in [16]) and improved machinability due to the small graphite spheroids, or as a precursor with good machinability before various hardening heat treatments.

However, in the austenitization step in the final heat treatment, the graphite dissolves and small voids are formed, again due to the several orders of magnitude higher diffusion rate for interstitial carbon compared to diffusion rates for iron and substitutional solutes. Figure 8 actually shows an ausferritic matrix with small voids at the former graphite positions.

The depth of focus of the SEM is ideally suited for investigating the resulting voids, see Fig. 9a and b. In 8b, residuals of graphite-nucleating hard inclusions (nitrides) are shown.

Already in 1937, Bonte [5] observed the void formation: "Even though the free graphite is later dissolved...voids remain in the finished product."

Void formation has been observed now and then for almost 80 years, but is in recent literature more or less overlooked. In the former Soviet Union, there were in the early 1960s a large number of observations of and discussion on the void formation, both in graphite containing irons and in steels [32-35].
One odd application of the phenomena is shown in a US patent dated 1959 [36], on an oil-permeable steel. The inventor states: "I have discovered that its porosity increases when it is subjected to repeated heating and cooling above and below its $\mathrm{A}_{1} \ldots$ " The idea of the patent is to repeat this cycling 40 times and thereby produce steel with 5 vol. $\%$ of voids/porosity.

One more recent paper [37] by Miura et al. utilized the void mechanism in heat-treated graphitic steel to create a model material for studying deformation at elevated temperatures.

The present authors are puzzled by the lack of recently reported observations of voids after the final heat treatments from groups working today with hardening heat treatments of ferritic ductile irons or graphitized steels.

The voids formed are not, from our experience, possible to heal during conventional austenitization although one early article by Hughes and Cutton [38] claimed the opposite: "...after the solution of the graphite spheroids, no porosity or voids were evident in the steel matrix."

There is an influence from voids on mechanical properties in ausferritic steels. We have so far only performed comparing Charpy V impact energy testing on the same rolled and austempered steel containing $0.5 \mathrm{wt} . \% \mathrm{C}$ and $3.8 \mathrm{wt} . \% \mathrm{Si}$, without or with prior graphitization. The steels were austempered at two different salt bath temperatures with the following mechanical properties for austempering without prior graphitization:

Higher $T_{\text {salt }}: \quad R_{\mathrm{p} 0.2}=1342 \pm 29 \mathrm{MPa} ; \quad R_{\mathrm{m}}=1688 \pm$ $13 \mathrm{MPa} ; A_{5}=12.8 \pm 0.8 \% ; K_{\mathrm{JIC}}=148 \pm 3.2 \mathrm{MPa} \sqrt{ } \mathrm{m}$. Lower $T_{\text {salt }}: R_{\mathrm{p} 0.2}=1464 \pm 18 \mathrm{MPa} ; R_{\mathrm{m}}=1910 \pm 20$ $\mathrm{MPa} ; A_{5}=9.7 \pm 0.8 \% ; K_{\mathrm{JIC}}=107 \pm 5.7 \mathrm{MPa} \sqrt{ } \mathrm{m}$.

The Charpy $V$ values for rolled and austempered samples without versus with prior graphitization are as follows: 
Higher $T_{\text {salt }}: 22.0 \pm 0.0 \mathrm{~J}$ versus $14.4 \pm 0.9 \mathrm{~J}(-35 \%)$. Lower $T_{\text {salt }}: 14.7 \pm 2.3 \mathrm{~J}$ versus $11.3 \pm 1.8 \mathrm{~J}(-23 \%)$.

Figure 10a and $\mathrm{b}$ shows a Charpy $\mathrm{V}$ fracture surface in two magnifications. Note the plastically expanded voids marked by arrows in Fig. 10b.

When spheroidal graphite cast iron is pre-quenched before austempering the ausferrite is refined by the secondary graphite spheroids, as earlier described. Voids formed during austenitization of graphitic steels do not refine the ausferrite during austempering. The structure in Fig. 8 is not of the refined "acicular ferrite"-type in Fig. 3. The difference is probably due to the finer dispersion of graphite from excess carbon (thus not dissolving forming voids) in the first case, compared to the voids formed from dissolved graphite in steel.

The only way of efficiently healing these voids (or closed casting porosity) is by subjecting the material to hot isostatic pressing (HIP), where the isostatic argon gas pressure in the range of $100-200 \mathrm{MPa}$ is acting on the outer surfaces at temperatures where the hot strength of the metal alloy is less than the applied pressure, thus causing local "superplasticity," creep, and diffusion bonding.

This method is currently extensively used for castings in expensive metal alloys that are difficult to cast without porosity such as Ti-6Al-4 V and Ni-based superalloys, to improve mechanical properties especially in fatigue. The process has usually been too expensive for most steels and cast irons if no other benefits can be concurrently obtained.

However, recent development of HIP equipment where the cooling rate of dense argon gas (with a density similar to water) can be increased from $<100 \mathrm{~K} / \mathrm{min}$ to $>1000 \mathrm{~K} /$ min enables quenching of workpieces after prior austenitization (whereby closed porosity is eliminated). Residual stresses are also much lower than after conventional quenching, since any residual stresses from prior process steps are eliminated by yielding and creep during austenitization, while new quenching stresses cannot be created until the workpiece has been cooled sufficiently for the material to become stronger than the compressive stresses from the isostatic pressure. Further the freedom to vary process temperature and alternate between promotion of nucleation at a lower and growth at a higher temperature can give better combinations of strength and ductility/toughness through creation of improved microstructures. These concurrent processes make hardening heat treatments in a HIP equipped with Uniform Rapid Quenching (URQ ${ }^{\mathrm{TM}}$ ) a cost-efficient method.

The current authors have investigated the combination of casting porosity elimination and creation of improved microstructures during austempering of ADI and ausferritic steels [1]. Recent use of this process with the aim to reach even higher ductility levels for the previously described rolled steel resulted in the following mechanical properties: $R_{\mathrm{p} 0.2}=1112 \pm 20 \mathrm{MPa} ; \quad R_{\mathrm{m}}=1445 \pm 24 \mathrm{MPa} ;$ $A_{5}=20.7 \pm 1.3 \%$.

The Charpy V values for samples rolled and austempered in HIP without or with prior graphitization are as follows: $40.8 \pm 4.4 \mathrm{~J}$ resp. $38.0 \pm 1.6 \mathrm{~J}(-7 \%)$, indicating that the influence from previous voids have been eliminated by power-law creep followed by diffusion bonding under the isostatic pressure of $170 \mathrm{MPa}$ during austenitization before quench.

\section{Summary}

In spheroidal graphite cast irons, the carbon redistribution between spheroids and the austenite creates no completely empty holes. Instead, the location in the matrix becomes oversized when some of the carbon from the spheroids is dissolved into the matrix. The worst-case scenario is when a ferritic or ferritized iron is heat-treated since all carbon required to satisfy the carbon solubility in the austenite at the austenitization temperature must then diffuse from the spheroids, while in ferritic-pearlitic or pearlitic irons some or all carbon may already be present in their respective matrices. If the equilibrium carbon content in austenite at austenitization temperature is $0.8 \mathrm{wt} \% \mathrm{C}$, one-third of the spheroid volume in a ferritic matrix is actually dissolved. It is surprising that this is seldom mentioned in the scientific ADI literature. The gaps created between graphite and matrix cause problems in ultrasonic testing of components, a subject discussed by Orlowicz et al. [39].

Ongoing work is investigating the potential for graphitic steels to substitute of the currently used free-cutting steels, sulfurized, or leaded. The graphitic high silicon steels are in many respects similar to ferritic ductile iron grades GJS400-18 and GJS-500-14. Their machinability ratings are promising, see comparison with steels in Fig. 11 [40].

The difference between graphitic steel and ferritic ductile iron is the size and amount of graphite nodules, $5 \mu \mathrm{m}$ versus $20-50 \mu \mathrm{m}$ in size and 2 vol.\% versus 10 vol.\% of graphite. However, size seems to be a minor factor in machinability. Katayama and Toda [28] reported equal machinability for dispersions of $5 \mu \mathrm{m}$ or $10 \mu \mathrm{m}$.

It might be presumed that forming and dissolving of the graphite spheroids to form voids may become a disadvantage in hardened steels. However, an US patent in 1997 [41] by Kawasaki Steel describes graphitized steels with good mechanical properties in conventionally quenched and tempered state, on condition that the graphite spheroids (and thus voids after hardening) are maximum $20 \mu \mathrm{m}$ in size.

One example is their alloy I containing $0.58 \mathrm{wt} \% \mathrm{C}$, 1.55 wt. $\%$ Si, 0.55 wt. $\% \mathrm{Mn}, 1.60$ wt. $\%$ Ni, 0.45 wt.\% Mo and $0.15 \mathrm{wt} . \% \mathrm{Cu}$. It was firstly graphitized to form $8.6 \mu \mathrm{m}$ 


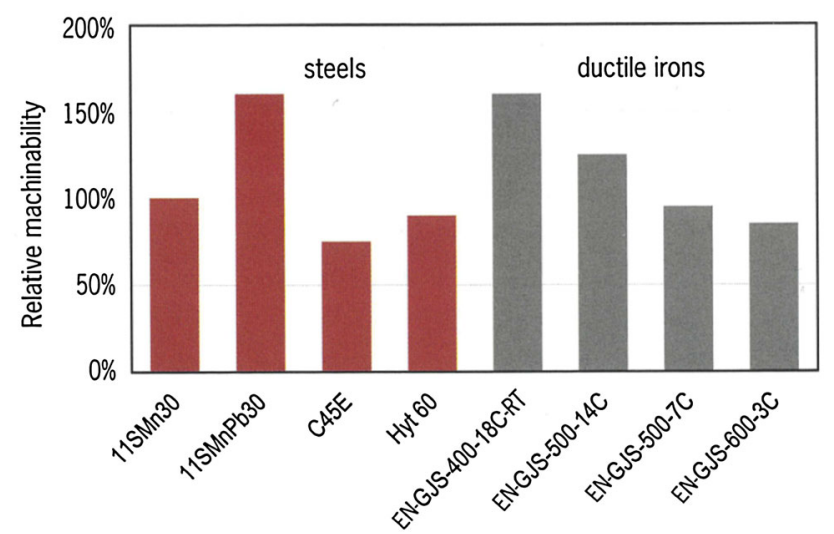

Fig. 11 Relative machinability of several ferrous materials determined as time to $0.3-\mathrm{mm}$ flank wear in turning with coated carbide inserts, according to ACO Eurobar [40]

graphite spheroids in ferrite matrix having hardness $221 \mathrm{HV}$ with very good machinability, followed by austenitization (and thus forming small voids), quenching and tempering to $400 \mathrm{HV}$ resulting in good properties: $R_{\mathrm{p} 0.2}=1200 \mathrm{MPa}$; $R_{\mathrm{m}}=1430 \mathrm{MPa} ; A_{5}=20 \%$ and fatigue resistance $643 \mathrm{MPa}$.

Austempering to ausferritic steel may also in this case result in even better properties than obtained for tempered martensitic steel.

Healing of porosity by HIP concurrently with improved hardening heat treatments using Uniform Rapid Quenching is currently developed.

The three presented microstructural highlights on solidstate transformation of graphite, namely secondary graphite formation in ductile cast irons, graphite formation in high silicon medium carbon steels, and void formation during dissolution of graphite, will hopefully inspire other metallographers.

Acknowledgements The authors acknowledge the financial support from Vinnova-project 2016-02837 "AusFerrit" within the Swedish strategic innovation program "Metalliska Material." The casting of rolling ingots by Smålands Stålgjuteri and the forging and rolling by Ovako is gratefully acknowledged.

Open Access This article is distributed under the terms of the Creative Commons Attribution 4.0 International License (http://creative commons.org/licenses/by/4.0/), which permits unrestricted use, distribution, and reproduction in any medium, provided you give appropriate credit to the original author(s) and the source, provide a link to the Creative Commons license, and indicate if changes were made.

\section{References}

1. R. Larker, P. Rubin, Austempering treatment in HIP improves ausferritic steels and ductile irons, in Heat Treat 2015,
Proceedings of the 28th ASM Heat Treating Society Conference, October 20-22, Detroit, Michigan, USA

2. J. Zimba, D.J. Simbi, T. Chandra, E. Navara, A dilatometry study of the austenitization and cooling behavior of ductile iron meant for the production of Austempered Ductile Iron (ADI). Mater. Manuf. Process. 19, 907-920 (2004)

3. K.D. Millis et al., The International Nickel Company: "Cast ferrous alloy". US-patent 2,485,760 (1949)

4. A. Hultgren et al., Värmebehandling av järn och stål (in Swedish), Figure 21 on page 48, Almqvist \& Wiksell/Liber AB, 1943

5. F.R. Bonte, M. Fleischmann, Development in graphitic steel for tools and dies. Met. Prog. 31, 409-413 (1937)

6. F.R. Bonte, Timken Company: "Ferrous alloys and method of manufacture". US-patent 2,087,764 (1937)

7. G.A. Stumpf, F.R. Bonte, Graphitic steel-its fabrication heat treatment and application to dies and punches. Steel 101, 34-39 (1937)

8. FR Bonte (1941) Graphitic steels - some of their more important applications. Steel 109 96, 111-112

9. F.R. Bonte, Timken, "Graphitic steel". US-patent 2,283,664 (1942)

10. F.R. Bonte, Timken. "Graphitic steels". US-patent 2,362,046 (1944)

11. C.R. Austin, M.C. Fetzer, Factors controlling graphitization of carbon steels at subcritical temperatures. Trans. AIME 35, 485-535 (1945)

12. W.E. Dennis, Heterogeneous nucleation of graphite in hypo-eutectoid steels. JISI 171, 59-63 (1952)

13. R.H. Hickley, A.G. Quarrell, The graphitization of steels at subcritical temperatures. JISI 178, 337-346 (1954)

14. R. Le Houllier, G. Bégin, A. Dubé, A study of the peculiarities of austenite during the formation of bainite. Metall. Trans. 2, 2645-2653 (1971)

15. Rubin-Materialteknik report 110407-441 (2011) for Ausferritic AB (in Swedish)

16. European standard EN 1563 "Founding-Spheroidal graphite cast irons", approved by CEN 2011-11-12

17. Rubin-Materialteknik report 110119-431 (2011) for Ausferritic $\mathrm{AB}$ (in Swedish)

18. Rubin-Materialteknik report 110308-439 (2011) for Ausferritic AB (in Swedish)

19. C.R. Azevedo, Effect of austenite grain size on kinetics of bainite reaction and its products morphology. M Sc Thesis (in Spanish), University of Sao Paulo (1991). http://www.teses.usp.br/teses/ disponiveis/3/3133/tde-11102007-165928/en.php

20. M. Hillert, Pressure-induced diffusion and deformation during precipitation, especially graphitization. Jernkontorets Ann. 141, 67-89 (1957)

21. K. He, A. Brown, R. Brydson, D.V. Edmonds, Analytical electron microscopy study of the dissolution of the $\mathrm{Fe}_{3} \mathrm{C}$ iron carbide phase (cementite) during a graphitisation anneal of carbon steel. J. Mater. Sci. 41, 5235-5241 (2006)

22. K. He, H.R. Daniels, A. Brown, R. Brydson, D.V. Edmonds, An electron microscopic study of spheroidal graphite nodules formed in a medium-carbon steel by annealing. Acta Mater. 55, 2919-2927 (2007)

23. A. Inam, R. Brydson, D.V. Edmonds, Effect of starting microstructure upon the nucleation sites and distribution of graphite particles during a graphitising anneal of an experimental medium-carbon machining steel. Mater. Charact. 106, 86-92 (2015)

24. J.X. Gao, B.Q. Wei, D.D. Li, K. He, Nucleation and growth characteristics of graphite spheroids in bainite during graphitization annealing of a medium carbon steel. Mater. Charact. 118, 1-8 (2016) 
25. D. Edmonds, R. Brydson, A. Inam, High-resolution metallography of a coarse microstructure: formation in the solid-state in steel. Mater. Perform. Charact. 5, 780-795 (2016)

26. A. Borruto, F. Felli, Process of graphitization by heat treatment (in Italian). Metall. Ital. 76, 218-225 (1984)

27. J.E. Harris, J.A. Whiteman, A.G. Quarrell, Decomposition of cementite in steels at subcritical temperatures. Trans. AIME 233, 168-179 (1965)

28. S. Katayama, M. Toda, Machinability of medium carbon graphitic steel. J. Mater. Process. Technol. 62, 358-362 (1996)

29. S. Katayama et al. (Assignee Nippon Steel), Fine graphite uniform dispersion steel excellent in cold machinability, cuttability and hardenability, and production method for the same. USpatent 5,830,285 (1998)

30. K. Oikawa et al., Medium-carbon steel having dispersed fine graphite structure and method for the manufacture thereof. USpatent $6,174,384$ (2001)

31. T. Iwamoto et al., Effects of boron and nitrogen on graphitization and hardenability in $0.53 \% \mathrm{C}$ steels. ISIJ Int. 42, S77-S81 (2002)

32. E.N. Pogrebnoi, Y.N. Taran, Effect of quenching on graphitization of cast iron and steel. Met. Sci. Heat Treat. Met. 2, 293-296 (1960)

33. K.P. Bunin, Mechanism and kinetics of phase transformation in cast iron. Met. Sci. Heat Treat. Met. 3, 384-391 (1961)
34. K.P. Bunin, A.I. Yatsenko, Dissolution of graphite in magnesium cast iron during heating. Met. Sci. Heat Treat. Met. 3, 211-213 (1961)

35. A.A. Baranov, K.P. Bunin, I.I. Pritomanova, Variation of the density of graphitized steel with heat treatment. Met. Sci. Heat Treat. Met. 3, 268-270 (1961)

36. S. Kawasaki. Oil Permeable Steel and Method for Manufacturing the same. US-patent 2,892,745 (1959)

37. H. Miura, T. Sakai, M. Okonogi, N. Yoshinaga, Deformation behavior of carbon steel with dispersed fine voids at elevated temperatures. Mater. Sci. Eng. A 483, 590-593 (2008)

38. M.A. Hughes, J.G. Cutton, Graphite in cold-rolled subcritically annealed hypoeutectoid steels. Trans. ASM 37, 110-135 (1946). (with discussion)

39. A.W. Orlowicz, M. Mróz, A. Trytek, Application of ultrasound in testing of heat-treated cast iron. Arch. Foundry Eng. 7, 13-18 (2007)

40. ACO Eurobar ${ }^{\mathrm{TM}}$ Technical Handbook for Continuous-Cast Ductile Iron (2015), Figure on page 38 in Chapter 6.8 "Machinability - the ductile iron advantage"

41. US-patent 5,648,044 (1997). T. Hoshino et al (Assignee Kawasaki Steel), Graphite steel for machine structural use exhibiting excellent free cutting characteristic, cold forging characteristic and post-hardening/tempering fatigue resistance 